that, Ruth had to go and faint, so here we are with three patients on our hands.

(DостоR looks over each patient, talking to them as he does so).

Doctor: Well, they look like they ought to get on all right now.

SAm: Yes, Bill fixed 'em all up.

My, but Ruth looks white! She looks like that man who was nearly drowned last summer.

Doctor: Sam, what would you do for a person who was nearly drowned?

SAM: I'll call Bill and keep cool.

Mother: Well, if you didn't keep any cooler than you did today, you wouldn't keep very cool.

Doctor: Bill, can't you give us a demonstration of artificial respiration? Sam.

Bill: I can try, Doctor. Get up here,

(Puts SAM on table, face downward, BrLL kneels on table beside SAM, presses with palms of hands on SAM's ribs, then releases pressure).

BILL: Now, this is the Schaefer method.

Ruth: Named after Miss Edna Shaefer?

Bill: Oh, no-named after some man a long time ago. (Continues explanation). This ought to be done about twelve or fourteen times a minute, but if you don't have a watch to time yourself, you can count. We learned a better way than that down at camp, though; when we press down we say "Out goes the water," and when we let up we say "In goes the air." That makes it about the right time. This method is better than the old Sylvester method, because it's so much easier to use.

Doctor: Well, Bill, I hope you will be a doctor when you grow up.

SAM (sitting up on edge of table, facing audience): Bill surely can do the doctoring till the doctor comes. (Then, nodding his head slowly) and the next time anything like this happens and I lose my head, I'm going to sit right down till I find it again!

Helen WagstafF

On the diffusion of education among the people rests the preservation and perpetuation of our free institutions.-DANIEL WEBSTER.

\section{EDUCATION IN ACCIDENT PREVENTION}

$\mathrm{E}$ $\mathrm{ACH}$ year 76,000 people are killed in the United States by accident, of whom twenty-five per cent or nineteen thousand are children under fifteen years of age. For every death there are twenty-six serious injuries-nearly two million people hurt and maimed and crippled. It is not a pleasant picture and it is a shameful one when we realize that this waste of life and limb is wholly unnecessary. It can be changed, if we will. The reason for this appalling loss is largely psychological, for we as a nation have not learned to think in terms of conservation as applied to human life. The secret of preventing accidents lies in teaching the children of the country to form habits in accordance with the ordinary laws of safety and common sense. With this in view the Education Section of the National Safety Council has been working since 1919 toward the development of education in accident prevention in the public and parochial schools of the country. The plan of making safety instruction an integral part of all regular curriculum subjects was worked out and its practicability demonstrated by Dr. E. George Payne of New York University, at that time Principal of the Harris Teachers' College in St. Louis. Other cities felt the need and developed similar work along the lines followed by St. Louis, notably Detroit, Cleveland, Cincinnati, Louisville, Milwaukee and several others, and achieved remarkable results in the reduction of the death rate of school children.

Briefly the plan is this. The various phases of safety in the home, in the school, at play and on the streets are used as themes for study and discussion in each of the conventional school subjects. For example, English class work offers an unlimited field for work in accident prevention through reading, composition, speeches, debates, etc. Drawing has an equally extensive scope for safety teaching through posters, construction, sand-table models, scrap books, bulletin-boards, etc., and an arithmetic class can use accident statistics for their city, state or country as a basis for graphs and problems, learning meanwhile the value of keeping accurate public record of accidents so that the extent of the accident 
situation may be known. Civics can include the study of municipal and governmental agencies for the protection of citizens such as the Police, Fire and Health Departments, Safety may be emphasized in geography through the study of U. S. Coast Service, the fighting of forest fires and protection from floods. Science may deal with poisons and their antidoes. This scheme involves no extra study periods and instead of being a drag on the teacher it makes her work easier because the accident theme stimulates the children's interest by relating their school work to their every day experience.

This, then, is the plan endorsed and adopted by the National Safety Council. In November 1922 the Education Section of the Council sent out to school superintendents in cities of ten thousand and over a questionnaire regarding the teaching of safety in their schools. This questionnaire met with a most unusual response, and a realization on the part of educators that this problem is a vital one for the schools to consider and act on. The following outline is an analysis of the answers received :

1. Schools with safety teaching:

a. Introduced as a part of the curriculum .................. 142

b. As a special subject.......... 37

c. Both as a special subject and as a part of the curriculum...... 40

d. Instruction in safety incidental... 57

Total.................... 276

2. Schools without safety teaching...... 17

3. Reply without information on this point 3

Total answers to date......... 296

4. Interest of child in school work stimulated by the use of the safety motive :

a. Those answering in the affirmative $\mathbf{1 3 6}$

b. Those answering in thenegative... 10

c. No answer .................. 133

5. Cities wishing further information in regard to plan of safety teaching.... 258

6. Cities not wishing further information in regard to plan of safety teaching..

7. No answer on this point.......... 25

8. Cities wishing to use the education committee as a clearing-house of safety information:

a. Affirmative ............... 199

b. Negative $\ldots \ldots \ldots \ldots \ldots \ldots \ldots$. 7

c. Wish further information before committing themselves ......... 21

d. No answer on this point......... 66

9. Cities having children's safety organizations in at least some of the schools
The plans of the Education Section involve a clearing-house for the exchange of material and information as to methods of safety instruction between schools. This will be largely. carried on by travelling exhibits, and safety films showing methods of safety teaching. We feel very strongly that the best way to develop education in accident prevention is to make available for all schools which are interested, plans and methods found successful by other schools.

The Statistical Bulletin of the Metropoli$\tan$ Life Insurance Company for November 1922 makes a report which is most encouraging to those interested in the development of safety instruction. It says:

"In view of the great and growing seriousness of the automobile situation as a whole, it is particularly gratifying to be able to report on one phase of the hazard which is actually declining. It appears from an analysis of the automobile fatalities among those insured in the Industrial Department of the Metropolitan Life Insurance Company that the rate has actually declined since 1919 among school boys and young men. From 1911 until 1919 there was a steadily increasing rise in every age group. The two years following 1919 have shown this change in the situation-a decline apparently concentrated in the ages between five and fifteen and to a lesser degree up to age twenty-five. On the ather hand, the rate among children under five and at the ages over twentyfive is increasing. The rate of increase is most marked among those over 65 .

"Does this mean that the propaganda carried on in the schools and through the public press has actually borne fruit? It is among the boys of school age that a very large proportion of the automobile fatalities occurs. If, as the figures indicate, the influence of the police, safety and school authorities has taught caution in the play habits of these boys, then a real step forward has been taken."

It is most significant that the period of reduction in automobile accidents to boys of school age should correspond to the campaign for education in accident prevention which began in 1919. A long step forward has indeed been taken and it is not too much to hope that the needless loss of life among American children will be cut down to a minimum in the course of the next ten years.

Mary Noel ArRowsmith 